African Crop Science Journal by African Crop Science Society is licensed under a Creative Commons Attribution 3.0 Uganda License. Based on a work at www.ajol.info/ and www.bioline.org.br/cs DOI: http://dx.doi.org/10.4314/acsj.v23i4.9

\title{
IMPACTS OF CLIMATE AND FARMING MANAGEMENT ON MAIZE YIELD IN SOUTHERN TANZANIA
}

\author{
H.I. MTONGORI ${ }^{1,2}$, F. STORDAL ${ }^{1}$, R.E. BENESTAD ${ }^{3}$, S.K. MOURICE ${ }^{4}$, M.E. PEREIRA-FLORES \\ and F. JUSTINO \\ ${ }^{1}$ Department of Geosciences, University of Oslo, P. O. Box 1022 Blindern 0315 Oslo, Norway \\ ${ }^{2}$ Tanzania Meteorological Agency, P. O. Box 3056, Dar es Salaam, Tanzania \\ ${ }^{3}$ The Norwegian Meteorological Institute, P. O. Box 43 Blindern, 0313 Oslo, Norway \\ ${ }^{4}$ Department of Crop Science and Production, Sokoine University of Agriculture, P. O. Box 3005, \\ Chuo Kikuu, Morogoro, Tanzania \\ ${ }^{5}$ Applied Meteorology Program Agricultural and Environmental Engineering Department, Federal Viçosa \\ University, Viçosa, MG36570 000, Brazil \\ Corresponding author: h.i.mtongori@geo.uio.no,hmtongori@gmail.com
}

(Received 19 August, 2015; accepted 24 November, 2015)

\begin{abstract}
Climate is one of the major factors controlling agricultural productivity in Africa. Changes in meteorological variables such as rising temperatures, changes in precipitation and increase in atmospheric carbon dioxide levels affect crop production. The objective of this study was to evaluate the impacts of climate change and variability, and crop management on yield of maize (Zea mays L.) grown in the southern part of Tanzania. Using the Decision Support System for Agrotechnology Transfer Cropping System Model (DSSAT-CSM), a series of sensitivity experiments were conducted to evaluate the response of maize yields to a range of principal changes in rainfall and temperatures. The sensitivities were estimated under two management practices, one with traditional farming practices, and the other with application of external farm inputs. Dry-spells during the growing season caused yield losses of all cultivars of up to $43 \%$ for the prolonged dry-spells of 20 days. Increased rainfall intensity, during vegetative and reproductive stages, caused the decrease in yield of 5 and 2\%, respectively. A 50-100\% decrease in rainfall intensity during the growing season caused a loss of yields between $40-100 \%$. Increased or decreased temperatures from the baseline values reduced or increased days to flowering and to physiological maturity, respectively. In addition, a decrease in temperature from the baseline values to $2{ }^{\circ} \mathrm{C}$ had an overall impact of yields loss for all cultivars. However, yields increased with an increase of temperature by up to $2.5^{\circ} \mathrm{C}$ (UH6303 and $\mathrm{H628}$ ) and $4.5^{\circ} \mathrm{C}$ (PAN691). Growing seasons with lower total rainfall $(<50 \mathrm{~mm})$ and temperature $\left(<1^{\circ} \mathrm{C}\right)$ from their climatological values, caused yield loss as much as 71 and $15 \%$, respectively for PAN691 cultivar. Generally, the impacts depended on the management, cultivar, soil characteristics, magnitude, timing and duration of the stress.
\end{abstract}

Key Words: DSSAT, rainfall, temperature, Zea mays

\section{RÉSUMÉ}

Le Climat est l'un des facteurs majeurs contrôlant la productivité agricole en Afrique. Les changements de données météorologiques tels que l'élévation des températures, variabilité dans les précipitations et l'augmentation du $\mathrm{CO}_{2}$ atmosphérique affecte la production agricole. L'objectif de cette étude était d'évaluer les impacts du changement climatique, de variabilité, et des pratiques agronomiques sur le rendement du maïs (Zea mays L.) cultivé dans la partie Sud de la Tanzanie. Une série d'expérimentations sur la sensibilité a été conduite au moyen 
du Système d'appui à la prise de décisions pour les transferts agro technologiques (DSSAT) afin d'évaluer la réponse en terme de rendement de maïs à une range de variabilités majeures dans les précipitations et les températures. Les sensibilités ont été estimées sous deux pratiques culturales, l'une avec les pratiques de culture traditionnelle et l'autre avec apport extérieur d'intrants agricoles. Des périodes durant la saison culturales a causé des pertes de rendement au niveau de tous les cultivars et ceci allant jusqu'à $43 \%$ pour des périodes sèches prolongées de 20 jours. Les augmentations de l'intensité de précipitations durant les périodes végétative et reproductive ont causé respectivement une diminution de 5 à $2 \%$ du rendement. Une réduction de l'intensité des précipitations de 50-100\% durant la saison culturale a causé une perte de rendement entre 40-100\%. L'augmentation ou la diminution des températures réduit ou augmente la date de floraison et de maturité. De plus, une diminution de température de $2{ }^{\circ} \mathrm{C}$ par rapport à la valeur moyenne a un impact significatif sur le rendement au niveau de tous les cultivars. Néanmoins, le rendement augmente lorsque la température augmente de $2.5^{\circ} \mathrm{C}$ (UH6303 and H628) et $4.5^{\circ} \mathrm{C}$ (PAN691). Les saisons culturales avec des précipitations globales $(<50 \mathrm{~mm})$ et $\left(<1^{\circ} \mathrm{C}\right)$ par rapport à leur valeurs climatologiques, ont causé respectivement une perte de rendement aussi élevée que 71 et $15 \%$ pour le cultivar PAN691. De façon générale, les impacts dépendent des pratiques culturales, du cultivar, des caractéristiques de sol, de la magnitude, du moment et de la durée du stress.

Mots Clés: DSSAT, pluie, temperature, Zea mays

\section{INTRODUCTION}

Among the major factors controlling agricultural productivity in Africa is climate (Sivakumar, 1988; Moore et al., 2012). While total seasonal rainfall is important in crop production (Mati, 2000; Cooper et al., 2008); the nature of within seasonal variability also has a major effect on crop productivity (Rowhani et al., 2011). For example, based on crop modelling and daily historical climate data for 80 seasons recorded over Machakos-Kenya, Cooper et al. (2008) found a general increase in maize yield as seasonal rainfall totals increased from 100 to $500 \mathrm{~mm}$, but found a considerable variation in yield resulting from contrasting patterns of within-season rainfall distribution. On the other hand, temperature increase over the season in an area suffering from water stress may increase evapotranspiration, which could trigger drought stress of plants (Mati, 2000; Tao et al., 2003). This may also reduce the growing period of the crop from sowing to maturity, resulting in yield reduction (Tao and Zhang, 2011).

Dry spells (Barron et al., 2003) and late onset/ early cessation of the growing season (Sivakumar, 1988; Mugalavai et al., 2008) have been identified as other limiting factors to crop yields. Dry spells may affect crop growth and final yields, even without significant reductions in seasonal rainfall totals (Barron et al., 2003). However, the severity of dry spells on plant growth and, hence yields, depends largely on the stage of plant development and crop type. Maize, for example, appears to be relatively tolerant to water deficits, during the vegetative growth stage, but not during tasselling and ear formation (Çakir, 2004).

The use of different adaptation strategies such as early or late planting, development of drought and high-temperature tolerant cultivars, the use of early or late-maturing cultivars, and inclusion of technology improvement sucha as irrigation and fertiliser application, in the farming systems have proved to lessen the severity of climate change and variability on final yields (Mati, 2000; Tao and Zhang, 2010; Li et al., 2011).

The objective of this study therefore, was to evaluate the impacts of climate change and variability on maize yield in southern Tanzania for using different crop managements practices.

\section{MATERIALS AND METHODS}

Study area. Four sites (villages), namely, Kichiwa, Welela, Ibumila and Matiganjola, were selected in Njombe region in the highlands of Southwestern Tanzania. The region is characterised by a unimodal climate regime, with one long rainy season (November to April), as represented by Kichiwa weather station (Fig. 1). The area has monthly maximum temperatures (Tmax) lower than $23.5^{\circ} \mathrm{C}$ for almost all months, except November and December which is higher $\left(24.7^{\circ} \mathrm{C}\right)$.

The minimum temperature (Tmin) in the area is between 12 and $15^{\circ} \mathrm{C}$ from November to April, 

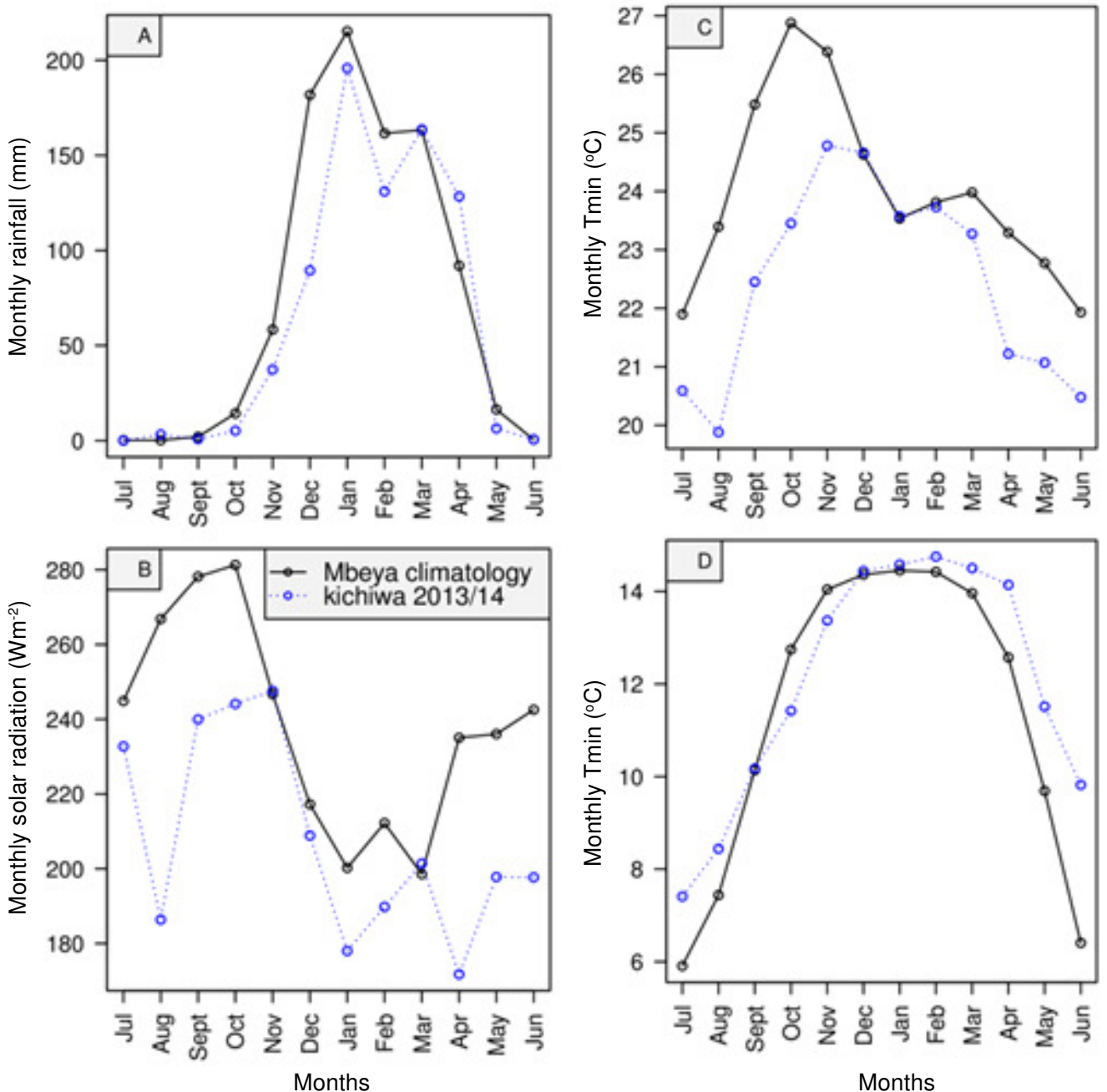

Figure 1. Annual cycle of rainfall, Tmax, Tmin and solar radiation for Kichiwa station as well as long term mean for the Mbeya station both in southern Tanzania. $A=$ monthly rainfall, $B=$ monthly solar radiation, $C=$ monthly maximum temperature and $D=$ monthly minimum temperature. Rainfall and temperature data are from the period 1981-2010, whereas solar radiation data are from 20102013.

and is lower than $8{ }^{\circ} \mathrm{C}$ during June-July. Solar radiation has a pronounced seasonal cycle, with values above $240 \mathrm{Wm}^{-2}$ from July to November, and around or below $200 \mathrm{Wm}^{-2}$ during JanuaryFebruary. The lowest solar radiation occurs during the rainy season, hence, it is associated with high cloud cover.

On-farm management data were obtained from three years (2011-2014) of the strategic intervention studies within the programme for Climate Change, Impacts, Adaptation and Mitigation (CCIAM) in Tanzania. Strategic
Intervention Studies were earlier part of the CCIAM programme and were initiated by Sokoine University of Agriculture (SUA), in collaboration with the two agro-input private companies, YARA and SYNGENTA.

Each farm was split into two parts such that a farmer used one part to plant and manage the farm in his traditional farming practice; hereafter termed as farmers practice (FP); and in the other part the farmer used external farm inputs such as fertilisers, herbicides, pesticides and advice on proper managements in order to improve the gap 
in yields, that is not climate related, a scheme that we have labelled YARA-SYNGENTA_SUA practice (YSSP).

DSSAT CERES-Maize plant model. The CERESMaize plant model, embedded in the Decision Support system for Agrotechnology Transfer Cropping System Model (DSSAT-CSM) v 4.5, simulates plant growth (e.g. phenology, daily growth and partitioning, plant nitrogen and carbon demands and senescence of plant materials); and yields (Jones et al., 2003). The minimum data set for model operation included daily weather during the growing season (maximum and minimum air temperature, rainfall and global solar radiation), soil characteristics at the start of the growing cycle (e.g. classification, $\mathrm{pH}$, organic carbon, drainage coefficients etc.); and other initial field conditions such as the previous crop and amounts of root and nodule. Other phenological information and management data needed in the model calculations included cultivar type, planting date, depth and method, fertiliser application and irrigation scheme.

Climate data. Historical climatic data for daily rainfall, solar radiation and maximum (Tmax) and minimum (Tmin) temperature used in this study were obtained from Iringa, Songea and Mbeya meteorological stations, operated by the Tanzania Meteorological Agency (TMA). In addition, daily weather data for one growing season (April 2013 to August 2014) were obtained from an Automatic Weather Station (AWS) installed at Kichiwa Dispensary, located at 9.04S, 34.85E (approximately $20 \mathrm{Km}$ away from all sites), and $1806.7 \mathrm{~m}$ above sea level.

Data for model calibration. Maize yield obtained from on-farm trials and weather data obtained from an AWS for the growing season 2013/14 were used for calibration of the model. Soil data to a depth of 0-40 cm (Table 1), collected in 2011, were used for two villages (Welela and Matiganjola), and soil information collected in 2010 were used for the remaining villages (Ibumila and Kichiwa). This is because soil samples prior to planting were taken only once at the beginning of the strategic intervention studies. Supplemental soil information, up to the depth of $93 \mathrm{~cm}$ was obtained from the Africa Soil Information System (AfSIS) database version 1.0 (Leenaars, 2012).

Maize varieties used in the simulations were chosen by farmers and these included UH6303 (Kichiwa and Welela villages), H628 (Ibumila village) and PAN691 (Matiganjola village). Other crop growth data for DSSAT calibration (Table 2) were obtained from the Tanzania Official Seed Certification Agency (TOSCA) crop variety experimental data lists (URT, 2008), and from the list of maize varieties from Kenya Seed Company LTD, available at http://www.kenyaseed.com. Management information (Table 3) recorded in

TABLE 1. Soil physical and chemical characteristics for each farm used in the calibration process for a study conducted at Kichiwa, Welela, Ibumila and Matiganjola villages in Njombe region

\begin{tabular}{lcccccccc}
\hline Farm & \multicolumn{3}{c}{ Location } & & & \multicolumn{3}{c}{ Soil physical and chemical characteristics (average) } \\
\cline { 2 - 3 } \cline { 6 - 7 } & Latitude & Longtude & $\begin{array}{c}\text { Altitude } \\
\text { (masl) }\end{array}$ & & Texture & $\mathrm{pH}_{\text {Cacl }}$ & $\begin{array}{c}\text { Organic } \\
\text { Carbon }(\%)\end{array}$ & $\begin{array}{c}\text { CEC } \\
\left(\mathrm{cmol} \mathrm{kg}^{-1}\right)\end{array}$ \\
\hline KC_YSSP & -9.03 & 34.9 & 1795 & & Sandy clay & 4.44 & 0.80 & 10.35 \\
KC_FP & -9.03 & 34.9 & 1796 & & Sandy clay & 4.11 & 0.68 & 11.23 \\
IB_YSSP & -9.27 & 35.1 & 1819 & & Sandy clay & 4.02 & 0.63 & 10.35 \\
IB_FP & -9.35 & 35.1 & 1818 & & Sandy clay & 4.10 & 0.67 & 11.23 \\
WL_YSSP & -9.08 & 34.87 & 1786 & & Sandy clay & 4.44 & 0.71 & 10.35 \\
WL_FP & -9.09 & 34.90 & 1793 & & Sandy clay & 4.11 & 0.63 & 11.23 \\
MT_YSSP & -9.46 & 35.02 & 1794 & & Sandy clay & 4.02 & 0.46 & 10.35 \\
MT_FP & -9.47 & 35.0 & 1794 & & Sandy clay & 4.10 & 0.44 & 11.23 \\
\hline
\end{tabular}

KC: Kichiwa, IB: Ibumila, WL: Welela and MT: Matiganjola 
TABLE 2. Model calibration information extracted from crop variety experimental data, for the maize varieties used in Southern Tanzania

\begin{tabular}{lrrr}
\hline Stage description & \multicolumn{3}{c}{ Maize variety } \\
\cline { 2 - 4 } & UH6303 & \multicolumn{1}{c}{ H628 } & PAN691 \\
\hline Days to $50 \%$ flowering & 92 & - & 102 \\
Days to maturity & $* 170-180$ & $150-180$ & $180-270$ \\
Optimal production altitude range (Masl) & $1200-1800$ & $1500-2100$ & $1700-2400$ \\
Potential grain yield (tha-1) & $9-10$ & $9-12$ & $7-8$ \\
\hline
\end{tabular}

*personal communication with Dr. Ramadhan Chambuya from SYNGENTA-Tanzania, an agronomist participated in the farm experiments. masl $=$ metres above sea level

TABLE 3. Management data used for model calibration in each farm in Southern Tanzania

\begin{tabular}{|c|c|c|c|c|c|c|}
\hline \multirow[t]{2}{*}{ Farm } & \multirow[t]{2}{*}{ Yields (kg ha-1) } & \multicolumn{5}{|c|}{ Management } \\
\hline & & Planting date & $\begin{array}{l}\text { Plant density } \\
\text { (plant } \mathrm{m}^{-2} \text { ) }\end{array}$ & $\begin{array}{l}\text { Planting depth } \\
\quad(\mathrm{cm})\end{array}$ & $\begin{array}{l}\text { Row spacing } \\
\text { (cm) }\end{array}$ & $\begin{array}{l}\mathrm{N} \mathrm{rate}^{\dagger} \\
\left(\mathrm{kg} \mathrm{ha}^{-1}\right)\end{array}$ \\
\hline KC_YSSP & 4800 & $2013-12-15$ & 4.4 & 6 & 73 & $64(36)$ \\
\hline KC_FP & 3100 & $2013-12-15$ & 4.1 & 6 & 75 & $35(15)$ \\
\hline IB_YSSP & 1100 & 2013-12-14 & 3.6 & 6 & 80 & $90(40)$ \\
\hline IB_FP & 2100 & $2013-12-14$ & 3.3 & 6 & 77 & $45(20)$ \\
\hline WL_YSSP & 5000 & $2013-12-16$ & 4.4 & 6 & 77 & $62(28)$ \\
\hline WL_FP & 2000 & $2013-12-16$ & 3.3 & 6 & 79 & $35(15)$ \\
\hline MT_YSSP & 1900 & $2013-12-15$ & 3.3 & 6 & 90 & $41(19)$ \\
\hline MT_FP & 1100 & $2013-12-15$ & 2.2 & 6 & 100 & $21(9)$ \\
\hline
\end{tabular}

KC: Kichiwa, IB: Ibumila, WL: Welela and MT: Matiganjola. ${ }^{+V a l u e s ~ i n ~ b r a c k e t s ~ r e p r e s e n t ~ s e c o n d ~ s p l i t ~ N ~ a p p l i c a t i o n ~}$

both practices, FP and YSSP, during the 2013/14 field experiments was used.

Model calibration and simulations. DSSAT crop models require genetic coefficients, which are specific for each cultivar to properly describe the processes related to growth development and grain production. These coefficients allow the model to simulate performance of diverse genotypes under different soil, weather and management conditions (Hunt et al., 1993).

Since neither of the cultivars was previously introduced in DSSAT, we created them in the genetic file (MZCER045.CUL) of DSSAT-CSM. Initial values of the genetic coefficients were obtained from the long maturity group cultivar (cultivar code 990001), already available in the DSSAT. Slight adjustments to these coefficients, were iteratively done to obtain simulated values close to observed values (Table 4). The values calibrated were days to anthesis and physiological maturity and grain yields.

Experimental setup. A modelling approach, using DSSAT, was to answer the "what if" questions about the response of maize yield to certain altered climatic conditions, reflecting either climate variability or change. Sensitivity analysis experiments were carried out such that the variation in yield output from the model was obtained by varying input weather data in the model (rainfall and temperature in this case). Other model inputs, including soil information, management and genetics coefficients, were maintained throughout the experiments. 
TABLE 4. Genetic coefficients for the three maize cultivars used in the CERES-Maize model, in a study in Southern Tanzania

\begin{tabular}{lcccccc}
\hline Cultivar & $\mathrm{P} 1\left({ }^{\circ} \mathrm{C}\right.$ day) & $\mathrm{P} 2$ (days) & $\mathrm{P} 5\left({ }^{\circ} \mathrm{C}\right.$ day) & $\mathrm{G} 2(\#)$ & $\mathrm{G} 3\left(\mathrm{mg} \mathrm{day}^{-1}\right)$ & PHINT $\left({ }^{\circ} \mathrm{C}\right.$ day) \\
\hline UH6303 & 310 & 0.5 & 800 & 580 & 6 & 38 \\
H628 & 315 & 0.5 & 800 & 470 & 4.5 & 38.9 \\
PAN691 & 330 & 0.5 & 800 & 450 & 5 & 50 \\
\hline
\end{tabular}

P1: thermal time from seedling emergence to the end of the juvenile phase (in degree days, ${ }^{\circ} \mathrm{Cday}$, above a base temperature of $8^{\circ} \mathrm{C}$ ) during which the plant is not responsive to changes in photoperiod. P2: delay in development (days) for each hour increase in photoperiod above the longest photoperiod at which development proceeds at a maximum rate (considered to be $12.5 \mathrm{~h}$ ). $\mathrm{P} 5$ : thermal time from silking to physiological maturity (degree days above a base temperature of $8^{\circ} \mathrm{C}$ ). $\mathrm{G} 2$ : maximum possible number of kernels per plant. G3: kernel filling rate during the linear grain filling stage and under optimum conditions $\left(\mathrm{mg} \mathrm{day}^{-1}\right)$. PHINT: phyllochron interval in thermal time (degree days) between successive leaf tip appearances

We performed a series of perturbation experiments covering the period from sowing to physiological maturity. The growing season for year 2013/14 (used in calibration) was taken as a baseline period for these perturbations. Firstly, for each day in a growing season, maximum temperature was raised or reduced by an offset ranging from -2 to $5{ }^{\circ} \mathrm{C}$, with an increment of 0.25 ${ }^{\circ} \mathrm{C}$. Secondly, each rainy day in the growing season was multiplied by a scaling factor ranging from 0.025 to 7 (equivalent to from $-97.5 \%$ reduction to $600 \%$ increase of rainfall intensity) That is, multiplicative factors less than one introduced rainfall reduction in the experiments; while those above one introduced rainfall increase. The simulations for the driest scenarios consisted of a set of runs, where the precipitation was multiplied by the factors $0.025,0.05,0.1$, and 0.2 , respectively.

For the simulations representing less severe drought up to wet scenarios, the scaling factors followed a more regular increment, with 0.25 difference beteen 0.25 and 7 . This choice allowed us to explore more impacts of reduced rainfall to yields as shown in Figures 2 and 3.

Thirdly, dry days were introduced for consecutive 10 or 20 day periods, ranging from 5 days before planting (i.e., $10^{\text {th }}$ December 2013), up to the expected maturity time (mid-June 2014). This covered all stages of the plant growing, i.e. at each step DSSAT was run and yields recorded before moving stress to the 10 or 20 days period. A similar approach as for dry days was used to introduce heavier or lighter rainfall events, but this was done at intervals of 20 days only.
Finally, we used meteorological data from years of abnormal rainfall (i.e. very wet and very dry), and temperature (i.e. very hot and very cool) as measured at Mbeya Meteorological Station to replace baseline weather data. Crop yields were estimated using observed rain or temperature records in four years, with either anomalous temperatures (warm or cold), or rain (dry or wet), as found in the Mbeya long term time series. We used those records, one by one, while keeping other meteorological variables as in the baseline case (Kichiwa AWS data), for the entire season from planting to physiological maturity of maize. We used weather records from Mbeya Station to obtain some extreme climatic conditions recorded in the past, due to lack of a long time series data set from the Kichiwa AWS. Mbeya Station has a similar climate regime as that of Kichiwa, especially rainfall. However, Kichiwa seems to be slightly cooler (Tmax) due to its higher attitude (1807 $\mathrm{m}$ above sea level) compared to that of Mbeya (1758 $\mathrm{m}$ above sea level).

For each of the climate perturbations listed above, DSSAT was run and yields and days to anthesis and physiological maturity were recorded. All climate data processing and plotting were done in R Software Version 3.1.2 (Team, 2012).

\section{RESULTS}

Model calibration. Calibration was challenging due to lack of some information about maize phenology from the experimental farms. However, supplementary information from literature and 


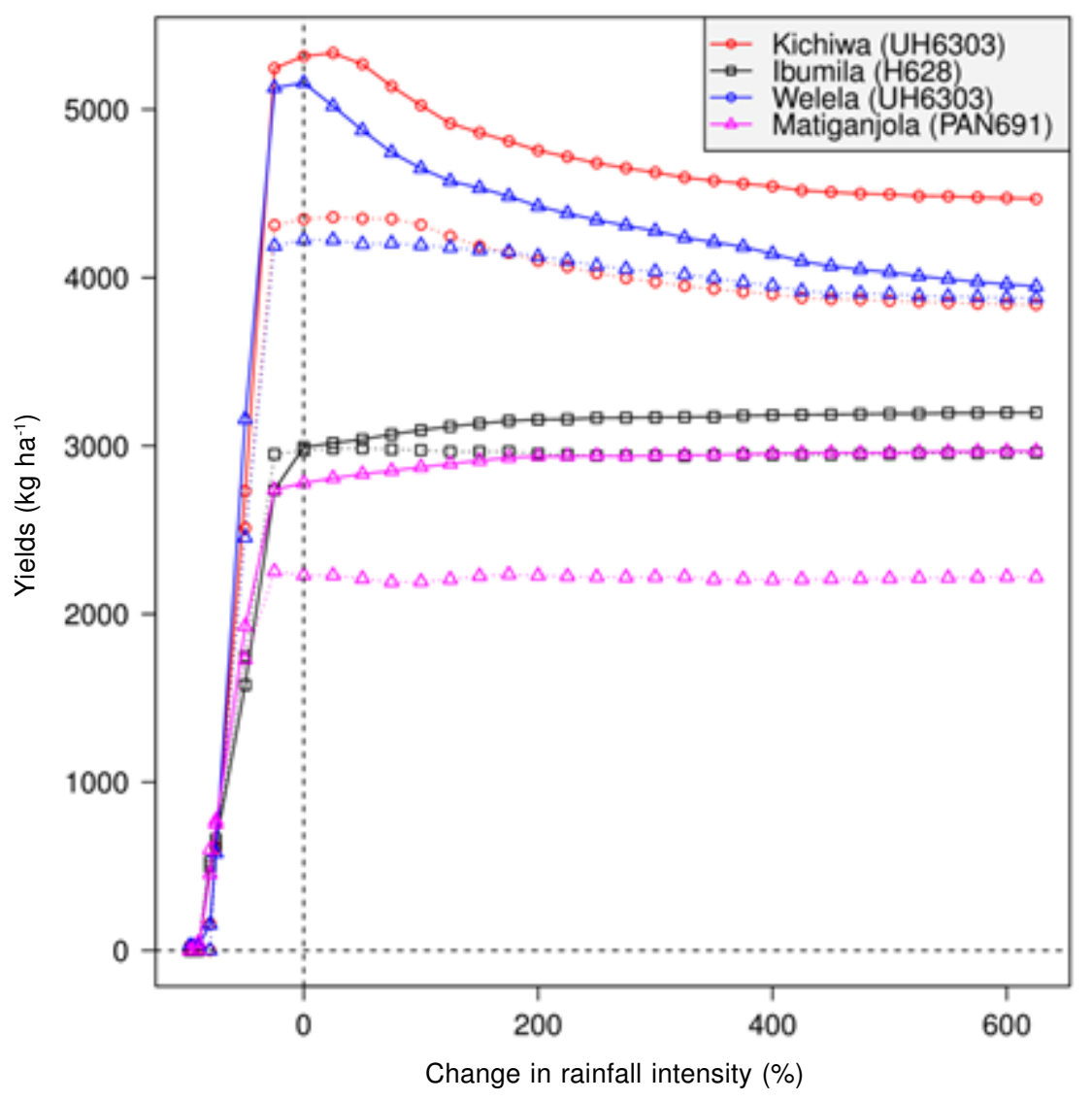

Figure 2. Change in maize yields with changing rainfall intensity for four farm fields (Kichiwa, lbumila, Welela and Matiganjola), solid lines represent YARA-SYNGENTA_SUA practice and dotted lines farmers practice. Vertical dashed line (black) indicates baseline rainfall values used in the simulations. Different symbols represent different cultivars as indicated in the legend.

other sources allowed us to get realistic simulation for days to anthesis and maturity (Table 5); with the exception of H628 whose actual days to anthesis was not recorded on farm field, yet we could not find alternative information in literatures. However, there was a substantial gap between observed and simulated yields, especially for H628 and PAN691 (Table 5). Perhaps the most common reason might be errors in field observations that arise from sampling and reporting, lack of representative soil data in the actual growing season, and other factors such as occurrence of extreme weather (e.g. hail) during the growing season. For this reason, more emphasis in calibration was put on days to anthesis and physiological maturity.
Sensitivity to seasonal rainfall intensity. Figure 2 presents maize yields with respect to changing seasonal rainfall for different farms, management and cultivars. Before turning to the impacts of rainfall, we noticed differences in yields between FP and YSSP management. Yields for YSSP management were higher than that of FP in all farms and maize cultivars. The average difference in yields for the simulations representing less severe drought to wet scenarios was $700 \mathrm{~kg} \mathrm{ha}^{-1}$ for UH6303 and PAN 691, and was $200 \mathrm{~kg} \mathrm{ha}^{-1}$ for H628 cultivars. In addition, UH6303 had higher yields compared to other two cultivars, yields for UH6303 in both management ranged between 4000 and $5200 \mathrm{~kg} \mathrm{ha}^{-1}$ while that of $\mathrm{H} 628$ and PAN691 ranged between 2000 and $3000 \mathrm{~kg} \mathrm{ha}^{-1}$. 

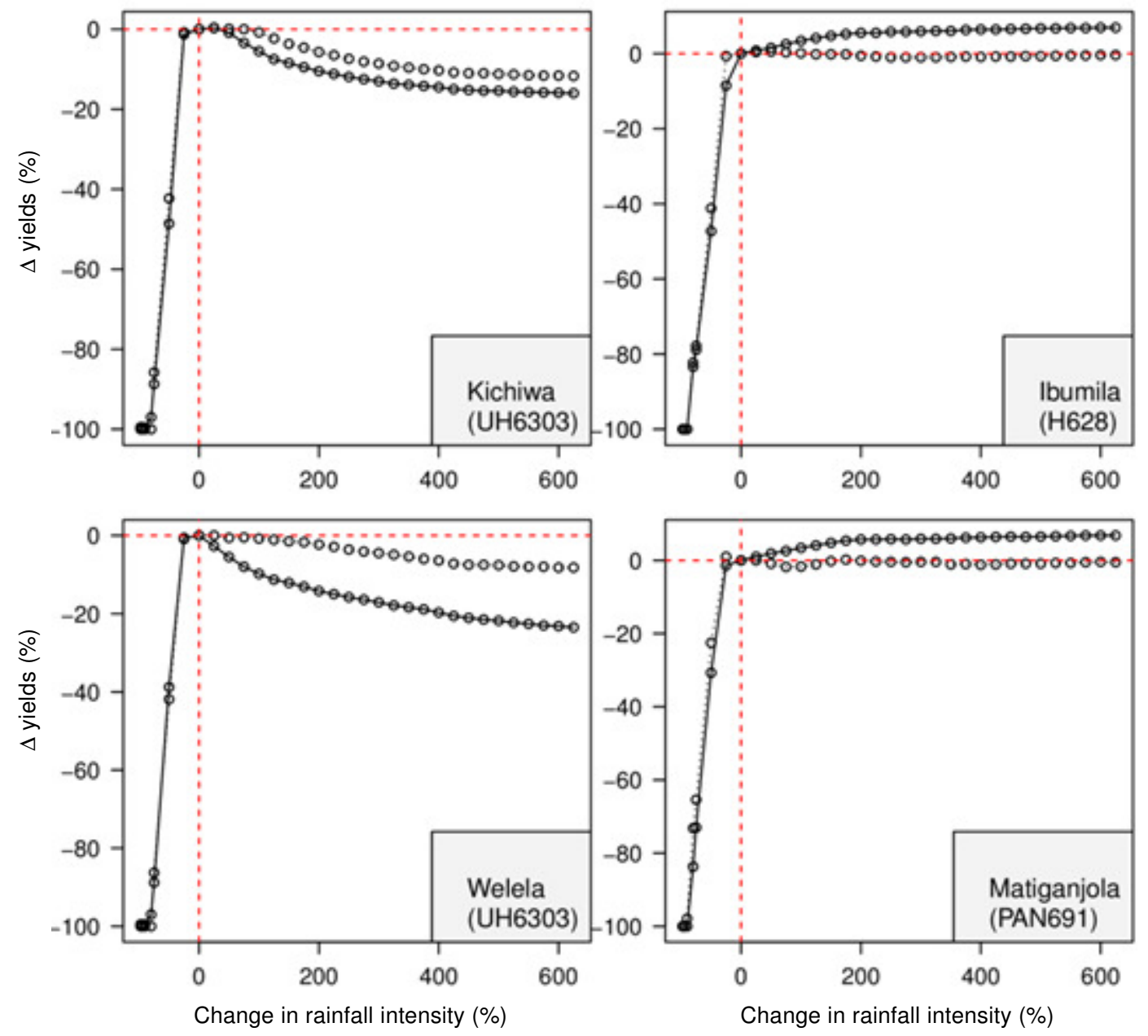

Figure 3. Percentage change in maize yields with change of rainfall intensity for different farms and cultivars in Southern Tanzania, Solid lines are for YARA-SYNGENTA_SUA practice and dotted lines for farmers practice. Vertical dashed line (red) indicates baseline rainfall values used in the simulations for all cultivar and farms. Horizontal dashed line (red) delineates the deviation of yields from baseline yields as a result of changing rainfall intensity. For each farm location planted maize cultivar is indicated in the bracket.

However, there were no prominent differences in yields between the cultivars and the two managements for driest scenarios. This indicates that in the driest climate neither FP nor YSSP is superior to the other.

Regarding precipitation, the optimum yield for the UH6303 cultivar was obtained for the changing rainfall in the range between -25 to $25 \%$. Thereafter, yields decreased with further increase in rainfall intensity for YSSP. However, the optimum yields were obtained in FP up to about $100 \%$ increase in rainfall. For all cultivars and farms, there was an abrupt drop in yields when rainfall was reduced below $-25 \%$. Although cultivars PAN691 and H628 were less affected by increased rainfall, their yields remained lower than UH6303.

Figure 3 shows the change in yields for the three cultivars at the four farms, with the two different managements, FP and YSSP. Generally, there was a decrease in yields by up to $20 \%$, with increase of rainfall for farms with UH6303. PAN691 and H628 cultivars hardly responded to rainfall in FP, but in YSSP yields took advantage of excess water resulting in a slight increase in yields. Decrease in rainfall intensity of about $75 \%$ had a 
TABLE 5. Observed versus simulated values of yields and days to $50 \%$ flowering and maturity for maize varieties used in the study conducted in Southern Tanzania

\begin{tabular}{|c|c|c|c|c|c|c|}
\hline \multirow[t]{3}{*}{ Stage description } & \multicolumn{6}{|c|}{ Maize variety } \\
\hline & \multicolumn{2}{|c|}{ UH6303(KC) } & \multicolumn{2}{|c|}{$\mathrm{H} 628(\mathrm{IB})$} & \multicolumn{2}{|c|}{ PAN691(MT) } \\
\hline & Observed & Simulated & Observed & Simulated & Observed & Simulated \\
\hline Days to $50 \%$ flowering & *92 & 94 & - & 92 & *102 & 101 \\
\hline Days to maturity & *176 & 178 & *176 & 179 & *190 & 194 \\
\hline Yield $\left(\right.$ tha $\left.^{-1}\right)$ & 4800 & 5316 & 1100 & 2971 & 1900 & 2779 \\
\hline
\end{tabular}

Yields are for Kichiwa (H6303), Ibumila (H628) and Matiganjola (PAN691) and for YARA-SYNGENTA_SUA practice only. *Values are estimated from experimental data presented in Table 2

disastrous effect, with yield losses of up to $50 \%$ for UH6303 and H628, and about 32\% for PAN691.

Sensitivity to dry spells or heavy rainfall events. Figure 4 demonstrates the impact of water stress on maize crop at different stages of growth. Induction of 10 dry days in the period, after flowering and before physiological maturity, reduced yields up to $6 \%$ for all cultivars. The yield loss due to dry days differed among cultivars during vegetative stages (Fig. 4 A-D). For example, H628 had higher yield losses of up to $28 \%$ through flowering (tasselling); while for PAN691 and UH6303, the reduction was about $6 \%$. However, there was a substantial deviation between FP and YSSP in yield changes at vegetative stages. At some points in UH6303 and PAN691 vegetative stages, FP indicated an increase in yields; while YSSP registered losses in yields. The longer dry spells (20 days) resulted in severe yield reductions, of about $20 \%$ for UH6303, 38\% for PAN691 and 43\% reduction for H628. For all cultivars and managements, reduction in yields was experienced right from early vegetative stages through flowering, to around filling stage (Fig. 4 E-H). The reduction was stronger for YSSP than for FP, although at some points in UH6303 FP had stronger reductions in yields compared to YSSP.

Figure 5 depicts the impact of rainfall intensity on yields at various stages of maize growth. Generally, increasing rainfall intensity increased yields for all three cultivars, in the reproductive stages (just after the flowering time to physiological maturity), but was the reverse in the vegetative stages. Only small differences (but not statistically significant) depicted in yields changes were between FP and YSSP, when the intensity was increased up to $50 \%$; but there was a deviation between the two practices with higher rainfall (Fig. 5A-D).

In Welela farm, for UH6303, FP management benefitted from higher precipitation during the vegetative stage; while the YSSP management got slightly lower yields (Fig. 5C). However, the opposite was depicted among the remaining farms. The magnitude of change seemed to be farm and cultivar specific. For example, Kichiwa (Fig. 5A) and Welela (Fig. 5C) farms planted the same cultivar (UH6303), but there was a yield reduction to about $5 \%$ for Welela farm compared to $1 \%$ for Kichiwa in the YSSP case. In Ibumila (Fig. 5B) and Matiganjola farms (Fig. 5D), reduction in yields during vegetative stages was depicted by the FP management only; a very minimal change towards increasing yields was revealed for YSSP management.

The impact of reduced rainfall intensity (Fig. $5 \mathrm{E}-\mathrm{H})$ presented effects similar to those of dry spells (20 days), though the magnitude of change differed with the intensity of stress introduced. For example, while reduction in intensity up to $50 \%$ showed a yield loss of up to $3 \%$ for all cultivars, a $75 \%$ reduction gave a loss of yields up to $10 \%$ for UH6303 and PAN691, and up to $32 \%$ for H628. On the contrary, PAN691 (but for FP management) gave increased yields during vegetative stages as a result of decreased rainfall intensity. 

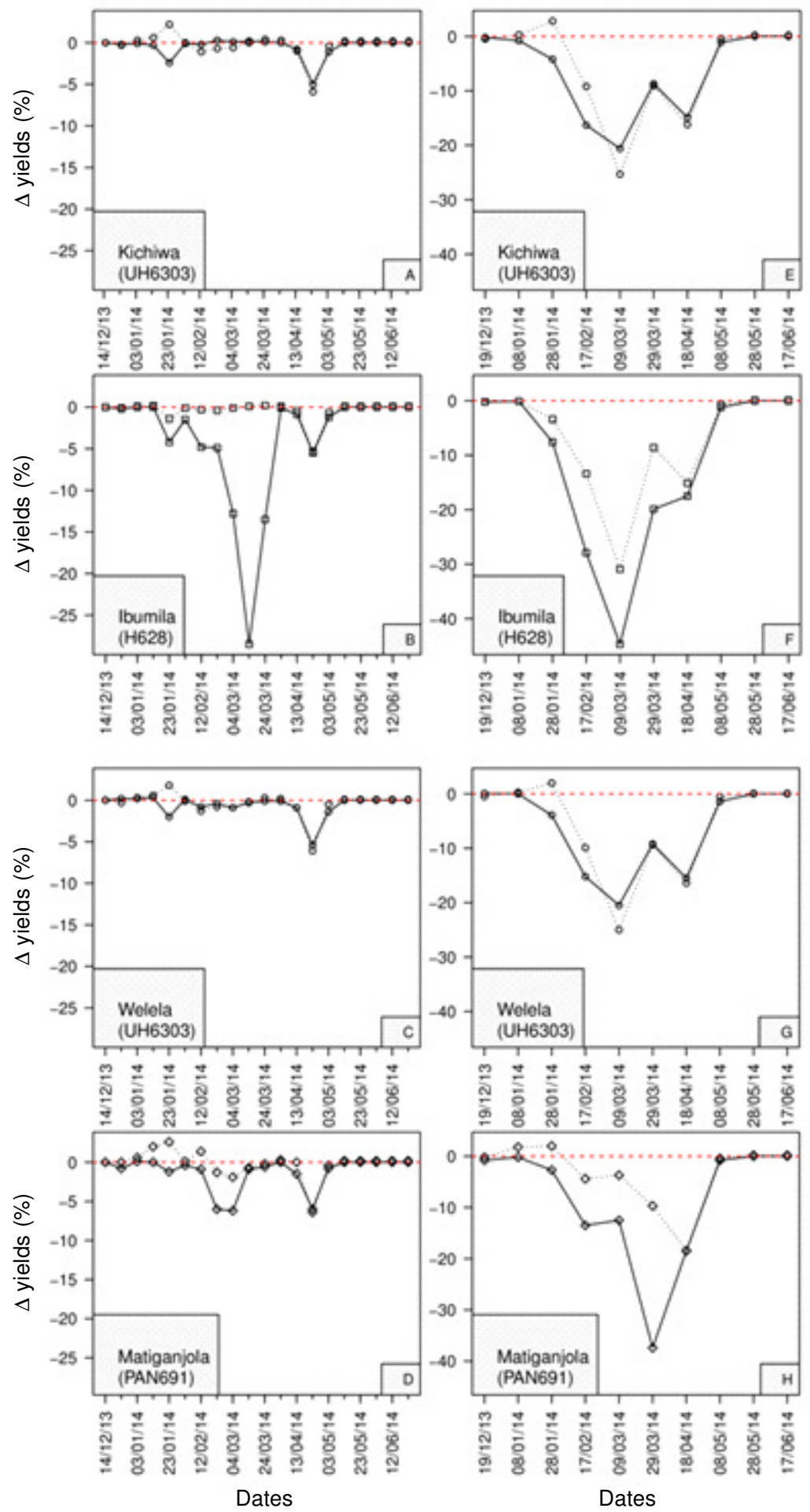

Figure 4. Percentage change in maize yields as a result of water stress in different stages of growing cycle in Southern Tanzania. Panels A-D represent stress for 10 consecutive days while panels $\mathrm{E}-\mathrm{H}$ represent stress for 20 consecutive days. Solid lines are for YARA-SYNGENTA_SUA practice and dotted lines for farmers practice. For each farm location the planted maize cultivar is indicated in the bracket. 

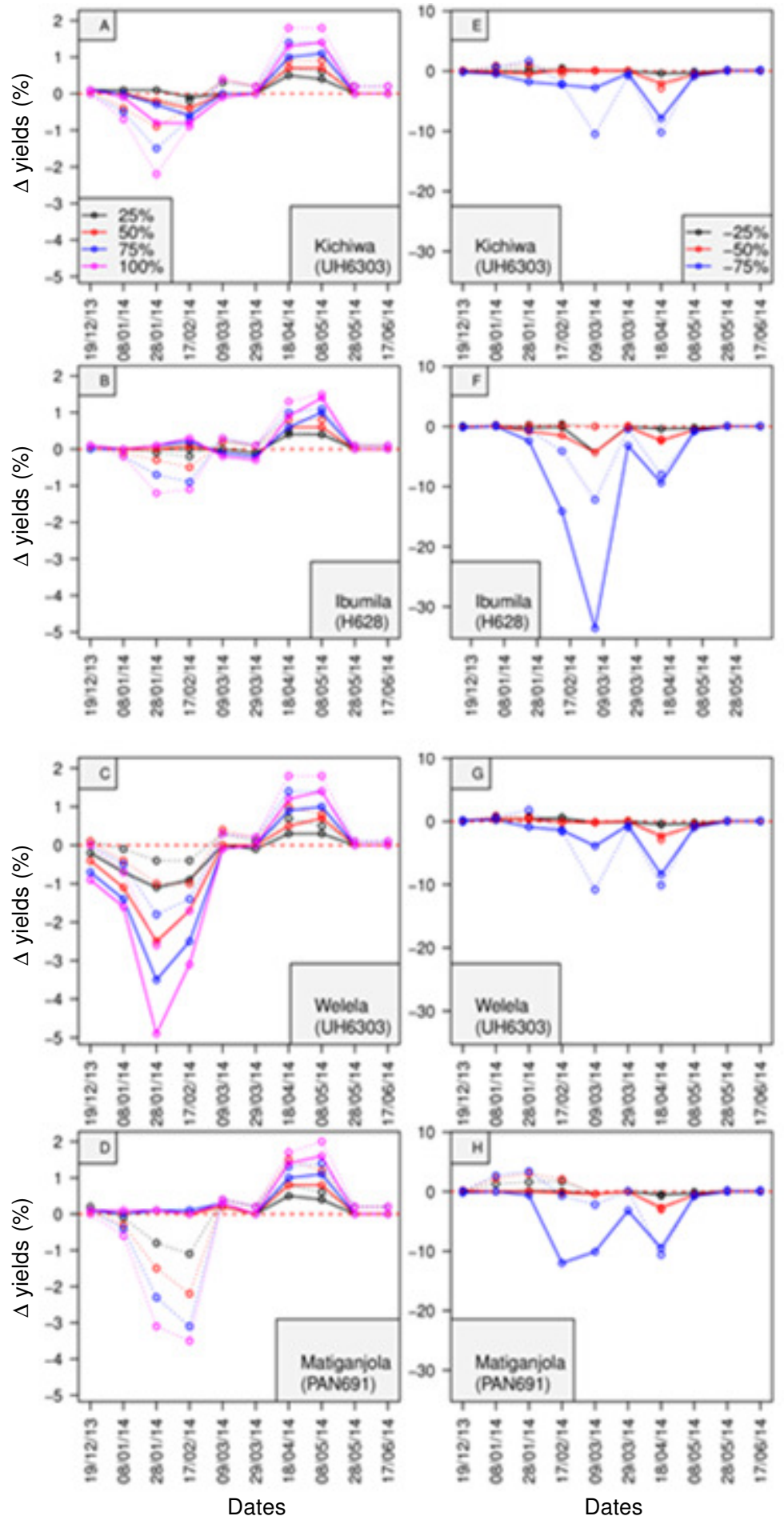

Figure 5. Percentage change in maize yields as a result of increased (decreased) rainfall intensity at different stages of the growing cycle in Southern Tanzania. Panels A-D represent different magnitudes of increased rainfall intensity (i.e increased by 25, 50, 75 and $100 \%$ ) for 20 consecutive days while panels $\mathrm{E}-\mathrm{H}$ represent different magnitudes of decreased rainfall intensity (i.e. reduced by 25,50 and $75 \%$ ) for 20 consecutive days. Solid lines are for YARA-SYNGENTA_SUA practice and dotted lines for farmers practice. For each farm location the planted maize cultivar is indicated in the bracket. 
Sensitivity to temperature changes. Figure 6 shows changes in number of days to flowering and maturity, with respect to changing seasonal temperature for different farms, management and cultivars. Generally, days to flowering were reduced or increased by an increase or a decrease in temperature, for all cultivars and managements. Likewise, days to physiological maturity decreased with temperature increase for all cultivars and management. The response to decreasing temperature differed across cultivars and managements, although there was a tendency to increase in days to maturity.
There was a general increase in yield with increase in temperature for up to $2.5^{\circ} \mathrm{C}$ for UH6303 and H628; and up to $4.5^{\circ} \mathrm{C}$ for PAN691 cultivars; and a decrease thereafter (Fig. 7). However, optimum yields (up to $10 \%$ increase) were expected when the temperature was raised, by $0.75,1.25$ and $3{ }^{\circ} \mathrm{C}$ for H628, UH6303 and PAN691, respectively. Although the extent of gain or loss in yields depended on cultivars, differences in farms also portrayed these differences in yields. For example, Kichiwa and Welela farms both planted with UH6303, but loss in yields for Welela for the lowest temperatures was higher (up to $25 \%$ ) than that of Kichiwa (only up to $10 \%$ ).
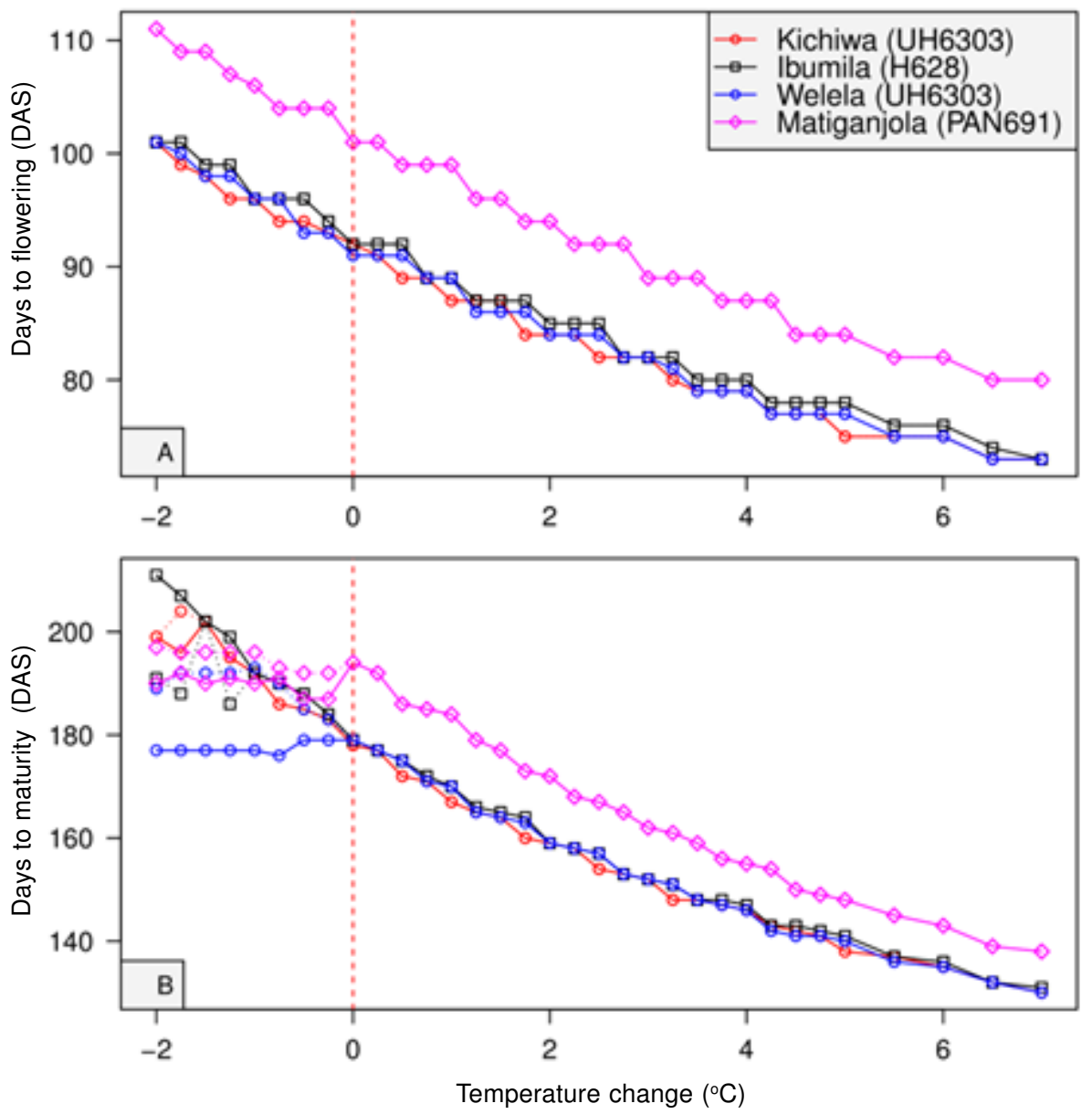

Figure 6. Impact of temperature change to the number of days to flowering (A) and physiological maturity (B) in Southern Tanzania. Solid lines are for YARA-SYNGENTA_SUA practice and dotted lines for farmers practice. Vertical dashed line (red) indicates baseline temperature values used in the simulations for all cultivars and farms. Different colours are for different farms and different symbols represent different cultivars as indicated in the legend. DAS: Days after sowing. 

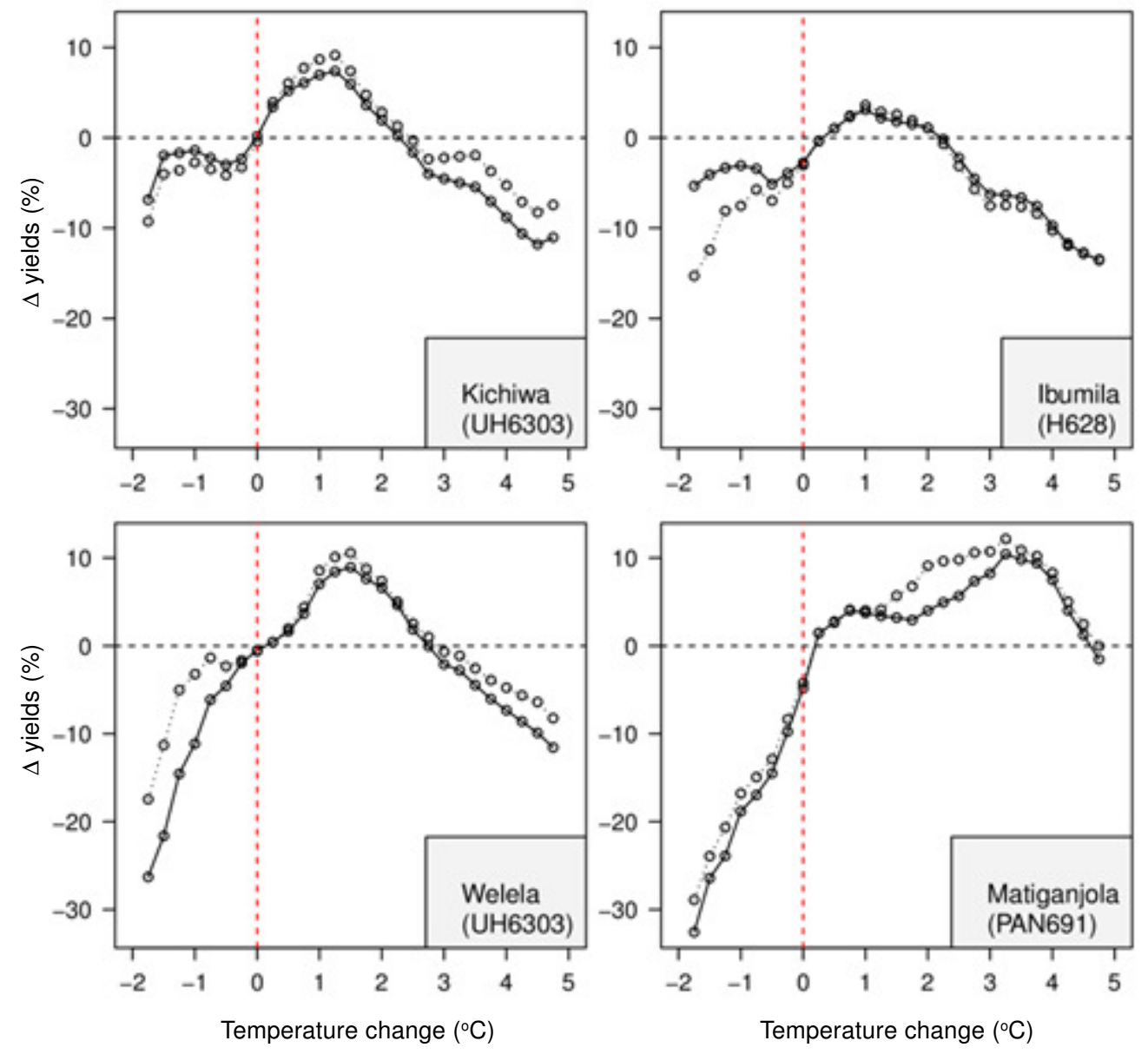

Figure 7. Percentage change in maize yields as a result of temperature change during growing cycle in Southern Tanzania. Black solid lines are for YARA-SYNGENTA_SUA practice and dotted lines for farmers practice. Vertical dashed line (red) indicates baseline temperature values used in the simulations for all cultivar and farms and horizontal dashed line (black) delineates the deviation of yields from baseline yields as a result of increasing (decreasing) temperature. Yields are smoothed by using 3 point running average.

Sensitivity to variability in temperature and precipitation. Table 6 shows the impact of abnormal rainfall (wetter and drier) and temperature (warmer and cooler) during growing season. All the cases had negative impacts on maize yield, but with the drier season leading to the highest yield loss (71\% for one of the farms). Colder conditions were the second worst, with a yield loss of $15 \%$. Warmer and wetter cases showed relatively minimal yield losses. There was a yield loss between YSSP and FP for all farms and abnormal weather conditions. Although in most cases YSSP presented higher yield loss than FP for wetter and drier conditions. FP had higher yield losses than YSSP in warmer and cooler conditions. In addition, drier and cooler conditions gave greater yield losses for Matiganjola farms (YSSP and FP) with the PAN691 cultivar.

Analysis of time series of the respective seasons with abnormal rainfall and temperature, portrayed more rain events (104 days) than the baseline (101 days), during wetter growing season. In most cases, the events were heavier than in the baseline, as reflected by the monthly mean values (Fig. 8A). There was heavy precipitation from mid-January to early February, the vegetative phase in the growing season. In 
the dry season, it rained less frequently (84 days) and the events were less intense (Fig. 8A). This was also evident in the monthly mean. Despite the less intense events, there were many dry days between early March and early April, which is the flowering and yield formation stages. These situations had a strong impact in reducing yields (Figs. 4 and 5).

In the warmer season (Fig. 8B), the time series showed that at the beginning of the growing season (December-February, vegetative stage), the temperature was similar to that of the baseline.

TABLE 6. Change in yields as a result of changing in distribution of rain and temperature during abnormal growing seasons in Southern Tanzania

\begin{tabular}{lccccccrr}
\hline $\begin{array}{l}\text { Extreme condition } \\
\text { (abnormal season) }\end{array}$ & \multicolumn{7}{c}{ Percentage change in yields (\%) } \\
\cline { 2 - 9 } & KC_YSSP & KC_FP & IB_YSSP & IB_FP & WL_YSSP & WL_FP & MT_YSSP & MT_FP \\
\hline Wetter(1997/98) & -5.5 & -3.3 & -4.7 & -3.3 & -9.6 & -4.4 & -2.6 & -7.2 \\
Drier(1953/54) & -60.7 & -57.1 & -64.7 & -56.9 & -61.5 & -59.5 & -71.4 & -63.2 \\
Warmer (2009/10) & -6.3 & -7.3 & -7.0 & -6.5 & -9.5 & -9.8 & -3.7 & -1.6 \\
Cooler(1955/56) & -3.1 & -5.3 & -6.3 & -8.2 & -7.3 & -7.7 & -11.7 & -15.6 \\
\hline
\end{tabular}
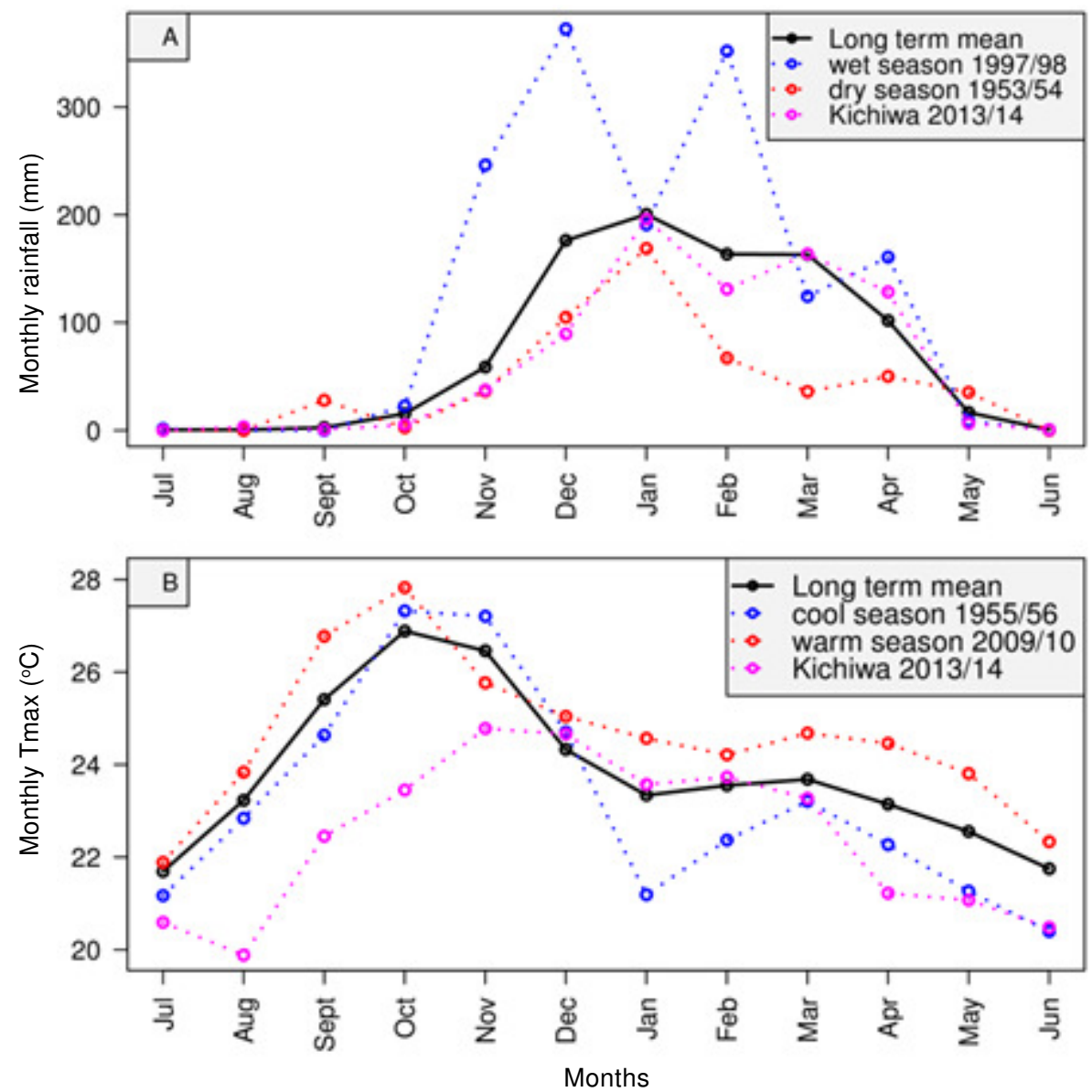

Figure 8. Annual cycle of rainfall (A) and $\operatorname{Tmax}(\mathrm{B})$ during growing seasons for different years regarded as abnormal in Southern Tanzania. Cool, warm, wet, dry and long term mean presented here are for the Mbeya weather station. 
TABLE 7. Simulated number of days to anthesis and physiological maturity as a result of changes in distribution of temperature during growing season in Southern Tanzania

\begin{tabular}{|c|c|c|c|c|c|c|c|c|}
\hline \multirow{2}{*}{$\begin{array}{l}\text { Temperature } \\
\text { phenomena }\end{array}$} & \multicolumn{8}{|c|}{ Days from sowing } \\
\hline & $\begin{array}{r}\text { KC_YSSP } \\
(\mathrm{UH} 6303)\end{array}$ & $\begin{array}{l}\text { KC_FP } \\
(\mathrm{UH} 6303)\end{array}$ & $\begin{array}{c}\text { IB_YSSP } \\
(\mathrm{H} 628)\end{array}$ & $\begin{array}{l}\text { IB_FP } \\
(\mathrm{H} 628)\end{array}$ & $\begin{array}{l}\text { WL_YSSP } \\
\text { (UH6303) }\end{array}$ & $\begin{array}{l}\text { WL_FP } \\
(\mathrm{UH6303)}\end{array}$ & $\begin{array}{c}\text { MT_YSSP } \\
\text { (PAN691) }\end{array}$ & $\begin{array}{c}\text { MT_FP } \\
\text { (PAN691) }\end{array}$ \\
\hline ADAP_baseline & 92 & 92 & 92 & 92 & 91 & 91 & 101 & 101 \\
\hline ADAP_cold & 97 & 97 & 98 & 98 & 97 & 97 & 107 & 107 \\
\hline ADAP_warm & 92 & 92 & 92 & 92 & 92 & 92 & 99 & 99 \\
\hline MDAP_baseline & 178 & 178 & 179 & 179 & 179 & 179 & 194 & 194 \\
\hline MDAP_cold & 185 & 185 & 186 & 186 & 185 & 185 & 203 & 193 \\
\hline MDAP_warm & 166 & 166 & 166 & 166 & 166 & 166 & 177 & 177 \\
\hline
\end{tabular}

Data are for the baseline case plus the warm and cold anomalous years in the Mbeya record (see text for details). ADAP denotes days to anthesis and MDAP days to physiological maturity
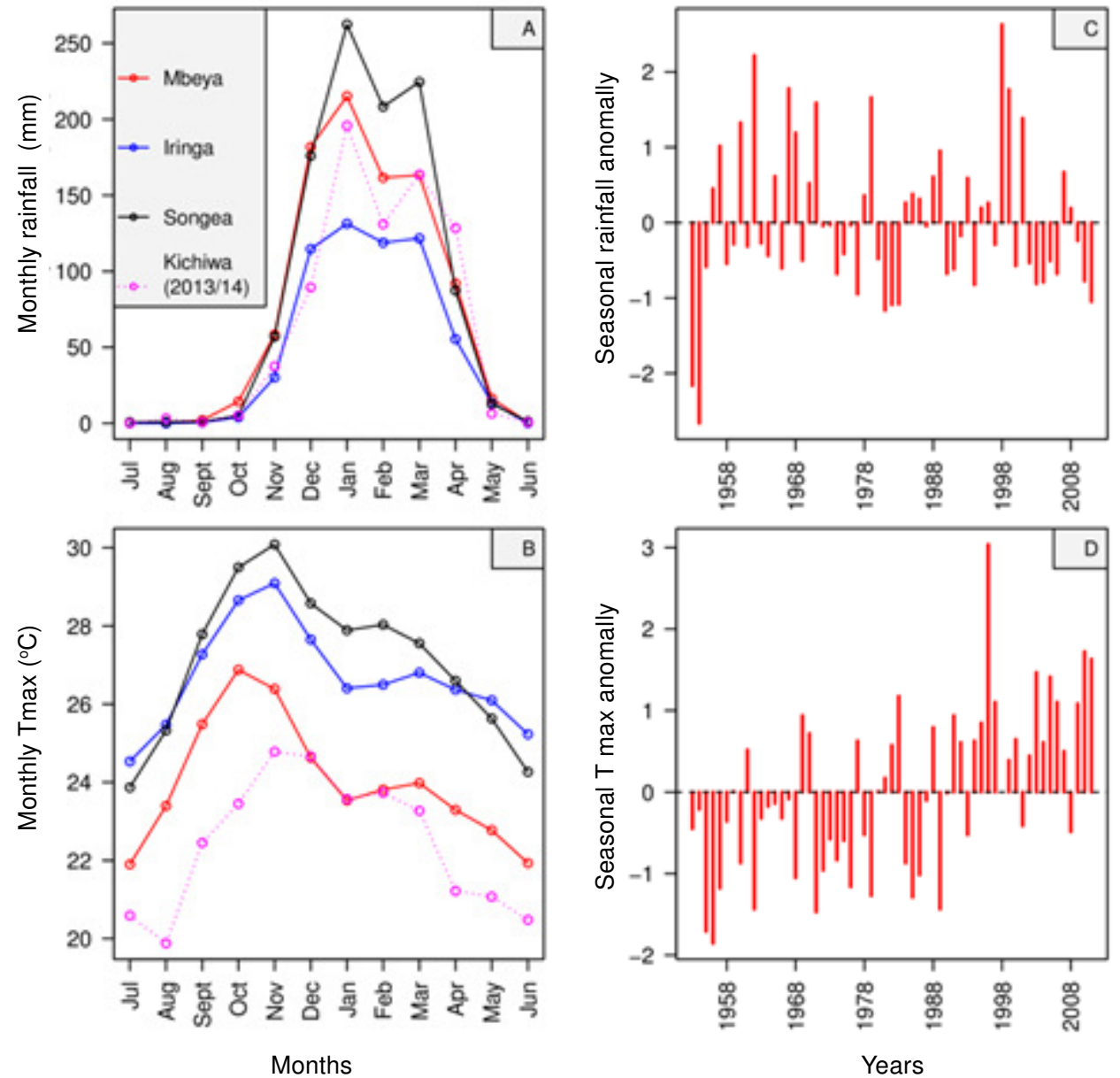

Figure 9. Annual cycle of rainfall and Tmax for maize production regions in southern Tanzania for period 1981-2010 (panels Aand $B$ respectively), and seasonal anomaly for rainfall and Tmax for Mbeya station (panels $C$ and $D$ respectively). Kichiwa station is in Njombe region. 
But during the reproductive stages (after March 14), temperatures were clearly higher than the baseline. In line with this, the simulated number of days to flowering was less affected than the simulated days to maturity (Table 7). Generally, two days were reduced for the plant to reach the flowering stage, and up to 17 days were reduced for the plant to reach physiological maturity in the warmer case. In the cold case, temperatures were lower starting before planting, through early vegetative stages (i.e. early December to February). It became slightly higher after flowering (between March and April), with respect to the reference temperature.

\section{DISCUSSION}

The difference in yields between YSSP and FP (Fig. 2) with changing rainfall intensity can be attributed to management used rather than soil and weather differences. The analysis of yields (not shown) when FP and YSSP management were interchanged, while using the same baseline weather and initial soil information, provided the mirror image of what was depicted in the previous analysis (Fig. 2). The interchange in initial soil information (keeping management and weather unchanged), did not change the previous findings in Figure 2; in fact soil changes enhanced yields with increasing rainfall intensity for YSSP management, and supressed yields for FP management. According to Mourice et al. (2014), the reason why farms with YSSP management experience higher yield losses compared to FP, could be because plants under high nitrogen supply are more vulnerable to water stress since they possess large leaf area through which a lot of water escapes via evapotranspiration. A similar case of obtaining greater losses in yields under recommended management compared to farmer practice for different cultivars was found by Tumbo et al. (2012).

It is well established that impacts of water stress or water logging on maize development and yields depend on the stage of development when it occurs, and the intensity and the duration of the stress (Barron et al., 2003). Although stress on plants and impacts on yields are experienced with increased or decreased rainfall intensity, the impacts depend on the intensity of the stress, and on how long and at which stage of the growing season the plant is exposed to that stress. Further, the impact depends on the cultivar and management used.

These findings are in agreement with the results obtained by Çakir (2004), who evaluated effects of water stress at different stages of vegetative and reproductive growth of maize. They found higher grain yields in the fully irrigated experiments and in the treatments with water stress during vegetative growth stage, and a strong loss in grain yields was obtained in the experiment with water stress during the sensitive tasselling and cob formation stages. Their results also depicted higher losses in grain yields when the prolonged water stress occurred during tasselling and early formation stages, probably due to reduced grain weight.

In our analysis, we got different simulated days to maturity within cultivars planted under FP or YSSP management (e.g. that observed for PAN691), although we used similar weather data and genetic coefficients to make all simulations. However, in the CERES models, plant life cycle is divided into several phases, and the rate of development of each phase is governed by particular conditions, e.g. daily growth rate is modified by temperature and assimilates availability (Jones et al., 2003). Therefore, if the plant runs out of resources, and if the grain growth rate is reduced below the threshold values for several days, growth is terminated prior to physiological maturity (Jones et al., 2003). In this case, probably difference in farm conditions (soil and management) were responsible for the shortage of important resources required for plant growth, and explaining some of these differences.

Our findings of increased yields for moderate temperature increases agree with the study of Thornton et al. (2009) and that of Lobell et al. (2011) that cooler and higher elevated areas get higher yields of maize in a future warmer climate, whereas yield reductions will be experienced in areas where the temperature commonly exceeded $28^{\circ} \mathrm{C}$. Likewise, reduction in yields, as a result of increased temperature, beyond an optimum level, is in agreement with the study by Badu-Apraku et al. (1982). Their findings showed that higher temperatures reduced grain yield per plant, and this reduction was entirely determined by a 
shorter duration of grain filling. Moreover, the increase in temperature after flowering (during the cold scenario) might have caused water stress due to increased evapotranspiration by the plants, at this reproductive stage. As a result, this may have been responsible for the slight loss in yields. The increase in temperature at this stage may be the reason that the number of days to maturity increased by only about 6 days compared to those reduced in warmer scenario (about 12 days).

The cultivars used in this study are grown in different areas of the southern Tanzania (Iringa, Mbeya, Njombe, Songea and Rukwa); which have different altitudes and climates (Fig. 9). The average growing season Tmax for Njombe (Kichiwa) and Mbeya ranged between 22.6 and $23.5{ }^{\circ} \mathrm{C}$; while that of Iringa and Songea was between 26 and $27^{\circ} \mathrm{C}$, respectively (Fig. 9 B). Thus, the average growing season temperature for Iringa and Songea had already exceeded the optimal production temperature for all three cultivars, but were within the range of getting positive yields for PAN691. This means that, for the current climate, UH6303 and H628 will experience slight reductions in yield in these areas. According to the findings of Thornton et al. (2009) and Lobell et al. (2011), it implies that three cultivars will experience yield losses under projected warmer climate and, therefore, may be less suitable for these regions.

In Figure 9D, it is clear that the last decade experienced warmer seasons for the Mbeya station. Since temperature is relatively homogeneous over a larger area, this has probably been the case for the neighbouring areas Njombe, Iringa and Songea; although the extent of increase might have been slightly different. Similarly, in the same station (Mbeya), there were several cases of drier growing season; in the last decade, compared with wetter seasons. Mtongori et al. (2015) found that the areas spanning one rain season (December - April) including southern Tanzania will experience a decrease in seasonal total rainfall by up to $30 \%$ from mid to the end of the $21^{\text {st }}$ Century. The depicted decrease in total precipitation is the result of decreasing number of rainy days, in some cases, in combination with decreasing daily rainfall intensity. This means that these areas are at higher risk to be impacted by long dry spells or drought. Therefore the combination of projected hotter and drier seasons over these areas is expected to cause serious losses of maize yields.

\section{CONCLUSION}

It is clear that both dry spells and decreased rainfall intensity in the growing season have negative impacts to yields as expected. The severity depends on the stage of growing when the stress occurs. In both managements regimes, UH6303 is vulnerable to water logging, especially when it occurs in the entire growing season; but YSSP management for PAN691 and H628 benefit from it, while FP shows no response. However, when water logging occurs in vegetative stage of maize developement, FP management records more yield loss for all cultivars compared toYSSP. In most cases, YSSP management is vulnerable to dry spells when at various stages of maize development compared to FP. Of the three cultivars, UH6303 can be a better choice to cultivate in these areas, as it is less sensitive to water stress than H628 and PAN691. But the challenge is that in some areas, such as Songea and Iringa, UH6303 is currently grown nearly beyond its optimal production temperature. So with an increase in temperature over these areas, cultivar (UH6303) will experience a severe yield loss during dry spells or when rainfall intensity decreases.

In this study, we did not use DSSAT to project yields for certain projections of climate change. Rather we used it as a tool for sensitivity studies of change in yields due to well defined changes in temperature and precipitation. Because we lacked some field data about phenology for these cultivars, genetic coefficients used in this study will not necessarily be realistic for simulation of future yields.

\section{ACKNOWLEDGEMENT}

This work was supported by the Climate Change Impacts Adaptation and Mitigation (CCIAM) Project funded through the Norwegian Embassy in Tanzania. We acknowledge the SUA/YARA/ SYNGENTA research team for providing the onfarm activities data. Special appreciation go to 
the research team leaders; Dr. Eva Mtengeti (SUA), Dr. Ramadhani Chambuya (SYNGENTA) and Mr. Kefa Maranga (YARA) who devoted their time to make sure that enough information about soil and farming management were available. The Tanzania Meteorological Agency (TMA) provided rainfall and temperature data.

\section{REFERENCES}

Badu-Apraku, B., Hunter, R.B. and Tollenaar, M. 1982. Effect of temperature during grain filling on whole plant and grain yield in maize (Zea mays L.). Canadian Journal of Plant Science 63:357-363.

Barron, J., Rockström, J., Gichuki, F. and Hatibu, N. 2003. Dry spell analysis and maize yields for two semi-arid locations in east Africa. Agricultural and Forest Meteorology 117: 23-37.

Çakir, R. 2004. Effect of water stress at different development stages on vegetative and reproductive growth of corn. Field Crops Research 89:1-16.

Cooper, P.J.M., Dimes, J., Rao, K.P.C., Shapiro, B., Shiferaw, B. and Twomlow, S. 2008. Coping better with current climatic variability in the rain-fed farming systems of sub-Saharan Africa: An essential first step in adapting to future climate change? Agriculture, Ecosystems \& Environment 126:24-35.

Hunt, L.A., Pararajasingham, S., Jones, J.W., Hoogenboom, G., Imamura, D.T. and Ogoshi, R.M. 1993. GENCALC: Software to facilitate the use of crop models for analysing field experiments. Agronomy Journal 85:10901094.

Jones, J.W., Hoogenboom, G., Porter, C.H., Boote, K.J., Batchelor, W.D., Hunt, L. A., Wilkens, P.W., Singh, U., Gijsman, A. J. and Ritchie, J.T. 2003. The DSSAT cropping system model. European Journal of Agronomy 18:235-265.

Leenaars, J. G. B. 2012. Africa Soil Profile Database, version 1.0. A compilation of geo-referenced and standardised legacy soil profile data for Sub Saharan Africa (with dataset). ISRIC report 2012/03. Africa Soil Information Service (AfSIS) project and ISRIC - World Soil Information, Wageningen, the Netherlands.
148 pp. http://www.isric.org/data/datadownload. Accessed 19 August 2013

Li, X., Takahashi, T., Suzuki, N. and Kaiser, H.M. 2011. The impact of climate change on maize yields in the United States and China. Agricultural Systems 104: 348-353.

Lobell, D.B., Banziger, M., Magorokosho, C. and Vivek, B. 2011. Nonlinear heat effects on African maize as evidenced by historical yield trials. Nature Climate Change 1:42-45.

Mati, B.M. 2000. The influence of climate change on maize production in the semi-humid-semiarid areas of Kenya. Journal of Arid Environments 46:333-344.

Moore, N., Alagarswamy, G., Pijanowski, B., Thornton, P., Lofgren, B., Olson, J., Andresen, J., Yanda, P. and Qi, J. 2012. East African food security as influenced by future climate change and land use change at local to regional scales. Climatic Change 110:823844.

Mourice, S.K., Rweyemamu, C.L., Tumbo, S.D. and Amuri, N. 2014. Maize cultivar specific parameters for Decision Support System for Agrotechnology Transfer (DSSAT) Application in Tanzania. American Journal of Plant Sciences 5(6):13.

Mtongori, H., Stordal, F. and Benestad, R. 2015. Evaluation of empirical statistical downscaling models' skill in predicting Tanzanian rainfall and their application in providing future downscaled scenarios. Journal of Climate doi:10.1175/JCLI-D-150061.1, in press.

Mugalavai, E.M., Kipkorir, E.C., Raes, D. and Rao, M.S. 2008. Analysis of rainfall onset, cessation and length of growing season for western Kenya. Agricultural and Forest Meteorology 148:1123-1135.

Rowhani, P., Lobell, D.B., Linderman, M. and Ramankutty, N. 2011. Climate variability and crop production in Tanzania. Agricultural and Forest Meteorology 151: 449-460.

Sivakumar, M. V. K. 1988. Predicting rainy season potential from the onset of rains in Southern Sahelian and Sudanian climatic zones of West Africa. Agricultural and Forest Meteorology 42:295-305. 
Tao, F., Yokozawa, M., Hayashi, Y. and Lin, E. 2003. Changes in agricultural water demands and soil moisture in China over the last halfcentury and their effects on agricultural production. Agricultural and Forest Meteorology 118:251-261.

Tao, F. and Zhang, Z. 2010. Adaptation of maize production to climate change in North China Plain: Quantify the relative contributions of adaptation options. European Journal of Agronomy 33:103-116.

Tao, F. and Zhang, Z. 2011. Impacts of climate change as a function of global mean temperature: Maize productivity and water use in China. Climatic Change 105:409-432.

Team, R. C. 2012. R A language and environment for statistical computing. R Foundation for statistical computing, Vienna, Austria, 2012. ISBN 3-900051-07-0.
Thornton, P. K., Jones, P. G., Alagarswamy, G. and Andresen, J. 2009. Spatial variation of crop yield response to climate change in East Africa. Global Environmental Change 19: 5465.

Tumbo, S.D., Kahimba, F.C., Mbilinyi, B.P., Rwehumbiza, F.B., Mahoo, H.F., Mbungu, W.B. and Enfors, E. 2012. Impact of projected climate change on agricultural production in semi-arid areas of Tanzania: A case of same district. African Crop Science Journal 20:453 $-463$.

United Republic of Tanzania (URT), 2008. Tanzania Variety list updated to 2008. Ministry of Agriculture food security and cooperatives. 64pp. http://www.agriculture. go.tz/publications.htm. Accessed 12 April 2015. 